\title{
Torsion Design Charts for Reinforced Concrete ReCtangular Members
}

\author{
By Liang-Jenq Leu' ${ }^{1}$ and Yu-Shu Lee ${ }^{2}$
}

\begin{abstract}
This paper presents design charts constructed from the softened truss model to facilitate the torsional design of reinforced concrete rectangular members. These design charts comprise a normalized failure mode diagram and a strength contour diagram. Given a reinforced concrete rectangular section, the former diagram can be used to determine the corresponding failure mode and the latter one the strength. These diagrams are plotted on the plane of two newly defined reinforcement indices including the longitudinal and transverse steel indices, which are introduced so that the design charts are independent of the section dimensions, the yield strength of reinforcement, and the compressive strength of concrete. The accuracy of the proposed design charts in the prediction of the failure mode and the torsional strength is comparable to that of the softened truss model, as demonstrated in the presented example, whereas the design charts are more computation efficient for use by designers than the softened truss model.
\end{abstract}

\section{INTRODUCTION}

The softened truss model is one commonly used method for investigating the torsional behavior of reinforced concrete. The design methods for torsion in the American Concrete Institute design code ("Building"' 1995) and the Comité Euro-International du Béton model code (CEB-FIP 1990) are based on the truss model with some simplifications. Detailed procedures for solving the set of equations in the softened truss model have been given in the literature (Hsu 1988, 1993; Collins and Mitchell 1991). However, these procedures are not suitable for structural design offices, as they are very lengthy and iterative.

Recently, simplifying the truss model, Rahal and Collins (1996) proposed a simple model for predicting the torsional strength of reinforced and prestressed concrete sections, in which no iterations are involved. This paper, along the same line but without making simplifications for the softened truss model, presents a normalized failure mode diagram and a strength contour diagram. With these two diagrams, the failure mode and the torsional strength for a reinforced concrete rectangular member can be determined immediately without tedious calculations. Thus, these diagrams are suitable for design purposes and can be considered as an alternative method to the current design methods in relevant design codes for the torsional design of reinforced concrete rectangular members.

\section{SOFTENED TRUSS MODEL FOR TORSION}

In this section, the softened truss model for torsion is briefly reviewed. [The reader is referred to Hsu (1993) for details.]

\section{Equilibrium Equations}

When a reinforced concrete beam is subjected to torsion, diagonal cracks form around the beam. Thus, after cracking, the beam can be idealized as a space truss as shown in Fig. 1(a), where an external torque $M_{x}$ is resisted by an internal torque resulting from the circulatory shear flow $q$. The shear flow $q$ occupies a zone, called the shear flow zone, which has a thickness of $t_{d}$.

\footnotetext{
${ }^{1}$ Assoc. Prof., Dept. of Civ. Engrg., Nat. Taiwan Univ., Taipei 10617, Taiwan.

${ }^{2}$ Grad. Student, Dept. of Civ. Engrg., Nat. Taiwan Univ., Taipei 10617 Taiwan.

Note. Associate Editor: David J. Stevens. Discussion open until July 1, 2000. To extend the closing date one month, a written request must be filed with the ASCE Manager of Journals. The manuscript for this paper was submitted for review and possible publication on January 21, 1999. This paper is part of the Journal of Structural Engineering, Vol. 126, No. 2, February, 2000. CASCE, ISSN 0733-9445/00/0002-0210_ $0218 / \$ 8.00+\$ .50$ per page. Paper No. 20089
}

Element $A$ in the shear flow zone [Fig. 1(a)] is subjected to a shear stress $\tau_{L t}=q / t_{d}$ as shown in Fig. 1(b). The in-plane equilibrium equations of this element can be expressed as

$$
\begin{gathered}
\sigma_{d} \cos ^{2} \alpha+\rho_{L} f_{L}=0 \\
\sigma_{d} \sin ^{2} \alpha+\rho_{t} f_{t}=0 \\
-\sigma_{d} \sin \alpha \cos \alpha=\tau_{L t}
\end{gathered}
$$

In (1) and (2), the steel ratios, $\rho_{L}$ and $\rho_{t}$, are defined, respectively, as

$$
\begin{gathered}
\rho_{L}=\frac{A_{L}}{p_{0} t_{d}} \\
\rho_{t}=\frac{A_{t}}{s t_{d}}
\end{gathered}
$$

where $A_{L}=$ total cross-sectional area of longitudinal steel; $A_{t}$ $=$ cross-sectional area of one transverse steel bar; $p_{0}=$ perimeter of the centerline of the shear flow zone; and $s=$ spacing between transverse steel bars. Also, $f_{L}$ and $f_{t}$ are the stresses of longitudinal steel and transverse steel, respectively; and $\sigma_{d}$ is the compressive stress of the concrete struts. It is assumed that $\sigma_{r}=0$; that is, the tensile stress of concrete is neglected. Finally, $\alpha$ is the angle of inclination of the concrete struts (or the $d$-axis) with respect to the $L$-axis.

The equilibrium equation relating $M_{x}$ to $\tau_{L t}$ takes the form

$$
M_{x}=2 \tau_{L t} t_{d} A_{0}
$$

where $A_{0}=$ area bounded by the centerline of the shear flow zone.

\section{Compatibility Equations}

The in-plane deformation of element $A$ of Fig. 1(a) should satisfy the three compatibility equations

$$
\begin{gathered}
\varepsilon_{L}+\varepsilon_{t}=\varepsilon_{d}+\varepsilon_{r} \\
\tan ^{2} \alpha=\frac{\varepsilon_{L}-\varepsilon_{d}}{\varepsilon_{t}-\varepsilon_{d}} \\
\gamma_{L t}=2\left(\varepsilon_{t}-\varepsilon_{d}\right) \tan \alpha
\end{gathered}
$$

According to the thin-walled tube theory, the relationship between the shear strain $r_{L t}$ and the rate of twist $\chi_{x}$ can be written as follows:

$$
\chi_{x}=\frac{p_{0}}{2 A_{0}} \gamma_{L t}
$$


(a)

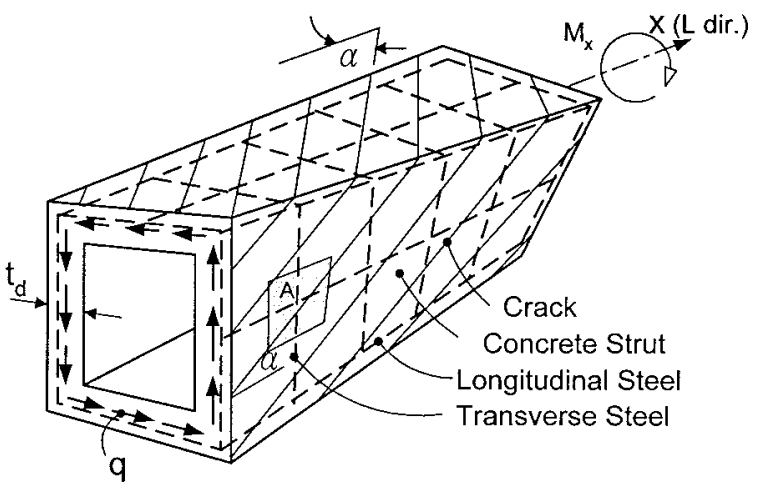

(b)

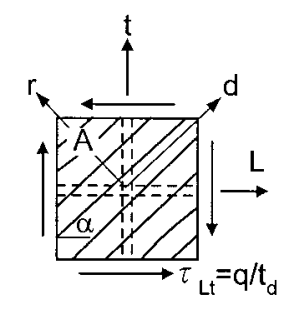

(c)

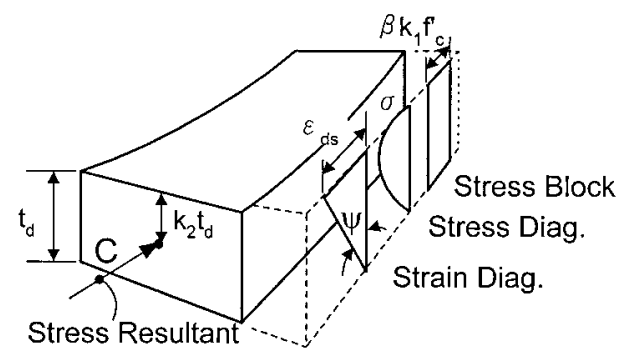

FIG. 1. (a) Space Truss for Torsion; (b) In-Plane Behavior; (c) Concrete Strut (Out-of-Plane Behavior)

When a member is subjected to torsion, twisting also produces warping in the wall of the member, which, in turn, causes bending in the concrete struts, as depicted in Fig. 1(c). This relationship is described by

$$
\psi=\chi_{x} \sin 2 \alpha
$$

where $\psi=$ curvature of the concrete struts. Hence, the thickness $t_{d}$ can be written in terms of $\psi$ and the maximum strain at the outer surface of the wall as follows:

$$
t_{d}=-\frac{\varepsilon_{d s}}{\psi}
$$

Eq. (12) is valid assuming the strain distribution through the thickness is linear, as shown in Fig. 1(c). The average strain $\varepsilon_{d}$ defined as the strain corresponding to the place at which the stress resultant is located, is assumed to be

$$
\varepsilon_{d}=\frac{\varepsilon_{d s}}{2}
$$

The reason for (13) is given in the paragraph that follows (17).

\section{Constitutive Laws of Concrete Struts and Steel}

Let the uniaxial stress-strain curve of the concrete struts be expressed by a parabolic curve

$$
\sigma=-\beta f_{c}^{\prime}\left[2 \frac{\varepsilon}{\varepsilon_{c 0}}-\left(\frac{\varepsilon}{\varepsilon_{c 0}}\right)^{2}\right]
$$

where $\varepsilon_{c 0}=-0.002 ; f_{c}^{\prime}=$ compressive strength; and $\beta=$ parameter representing the softening effect due to tension cracking in the perpendicular direction. The softening parameter proposed by Vecchio and Collins (1986) is adopted in this study, which takes the form

$$
\beta=\frac{1}{0.8+170 \varepsilon_{r}} \leq 1
$$

where $\varepsilon_{r}=$ principal tensile strain of the concrete struts. Notice that (14) may not be very accurate when $f_{c}^{\prime}>35 \mathrm{MPa}$.

The concept of stress block still applies for the concrete struts. Therefore, the average stress of the concrete struts $\sigma_{d}$, as shown in Fig. 1(c), is given by

$$
\sigma_{d}=-k_{1} \beta f_{c}^{\prime}
$$

where the nondimensional coefficient $k_{1}$ is defined as the ratio of the average stress to the peak stress $-\beta f_{c}^{\prime}$. Given (14), to obtain a force equivalent to that produced by the stress diagram requires $k_{1}$ to be of the form

$$
k_{1}=\frac{\varepsilon_{d s}}{\varepsilon_{c 0}}\left(1-\frac{\varepsilon_{d s}}{3 \varepsilon_{c 0}}\right)
$$

Finally, the resultant per unit width $C$ of the softened compression stress block has a magnitude of $C=k_{1} \beta f_{c}^{\prime} t_{d}$, and its position is theoretically located at a distance of $k_{2} t_{d}$ from the extreme compression fiber. The value of $k_{2}$ is in the range of 0.4-0.5. As discussed in Hsu (1993), the assumption of $k_{2}=$ 0.5 will simplify the model and have only a slight effect on the accuracy. This assumption justifies the use of (13).

The constitutive law of steel is assumed to be elastic-perfectly plastic. Young's modulus for both longitudinal and transverse steel is denoted by $E_{s}$, yield strength by $f_{L y}$ and $f_{t y}$, respectively, and yield strain by $\varepsilon_{L y}$ and $\varepsilon_{t y}$, respectively.

\section{Geometry Equations}

Some useful equations regarding $A_{0}$ and $p_{0}$ are given as follows:

$$
\begin{gathered}
A_{0}=A_{c}-\frac{p_{c}}{2} t_{d}+\xi t_{d}^{2} \\
p_{0}=p_{c}-4 \xi t_{d}
\end{gathered}
$$

where $A_{c}$ and $p_{c}=$ area and perimeter of the cross section, respectively. The value of the parameter $\xi$ is geometry-dependent; for example, $\xi=1$ if the cross section is rectangular, and $\xi=\pi / 4$ if it is circular.

\section{Rearrangement of Equations}

Some equations obtained from combining the above equations are given below for later use.

From (3) and (6), it can be derived that

$$
M_{x}=-\sigma_{d} t_{d} A_{0} \sin 2 \alpha
$$

It can be derived from (11) and (12) that $\chi_{x}=-\varepsilon_{d s} /\left(t_{d} \sin \right.$ $2 \alpha$ ), which is then substituted into (10) to yield

$$
\varepsilon_{d s}=-\frac{t_{d} p_{0}}{2 A_{0}} \gamma_{L t} \sin 2 \alpha
$$

From (8) and (9), $\gamma_{L t}=2\left(\varepsilon_{L}-\varepsilon_{d}\right) \cot \alpha$, the substitution of which into (21) yields

$$
\varepsilon_{d s}=-\frac{2 t_{d} p_{0}}{A_{0}}\left(\varepsilon_{L}-\varepsilon_{d}\right) \cos ^{2} \alpha
$$

Substituting $\cos ^{2} \alpha$ from (1) and $\varepsilon_{d s}$ from (13) into (22) yields

$$
\varepsilon_{L}=\varepsilon_{d}+\frac{A_{0} \sigma_{d}}{A_{L} f_{L}} \varepsilon_{d}
$$

Substituting $\gamma_{L t}$ from (9) into (21) yields 


$$
\varepsilon_{d s}=-\frac{2 t_{d} p_{0}}{A_{0}}\left(\varepsilon_{t}-\varepsilon_{d}\right) \sin ^{2} \alpha
$$

Substituting $\sin ^{2} \alpha$ from (2) and $\varepsilon_{d s}$ from (13) into (24) yields

$$
\varepsilon_{t}=\varepsilon_{d}+\frac{A_{0} \sigma_{d} s}{p_{0} A_{t} f_{t}} \varepsilon_{d}
$$

\section{FAILURE MODE DIAGRAM}

\section{Failure Modes}

Depending on the percentages of steel in the longitudinal and the transverse directions, a reinforced concrete cross section subjected to torsion may fail in the following four modes:

1. Underreinforced element: Both the longitudinal steel and the transverse steel yield before the crushing of concrete.

2. Element partially underreinforced in $t$-direction: Transverse steel yields before the crushing of concrete; longitudinal steel does not yield.

3. Element partially underreinforced in $L$-direction: Longitudinal steel yields before the crushing of concrete; transverse steel does not yield.

4. Overreinforced element: Concrete crushes before the yielding of steel in either direction.

Notice that in this study failure is reached when $\varepsilon_{d s}=\varepsilon_{c u}=$ -0.0035 , where $\varepsilon_{c u}$ is the ultimate (crushing) strain of concrete.

Given a reinforced concrete cross section and the material properties of steel and concrete, a failure mode diagram can be constructed on the $\rho_{L}-\rho_{t}$-plane to indicate the appropriate failure mode. The diagram is divided into four regions by two solid curves, or failure boundaries, $I_{L}$ and $I_{t}$; Regions (I)-(IV) correspond to the above four failure modes, respectively. Consider a rectangular cross section with a width of $25.4 \mathrm{~cm}$ and a depth of $38.1 \mathrm{~cm}$; the material properties are $f_{c}^{\prime}=27.47 \mathrm{MPa}$, $E_{s}=200 \mathrm{GPa}$, and $f_{L y}=f_{t y}=311.86 \mathrm{MPa}$. The failure mode diagram is shown in Fig. 2; the construction procedures are detailed below.

\section{Procedures for Constructing Failure Boundaries}

Curves $I_{L}$ and $I_{t}$ in Fig. 2 are called failure boundaries. Curve $I_{L}$ corresponds to the condition of $\varepsilon_{L}=\varepsilon_{L y}$ when $\varepsilon_{d s}=$

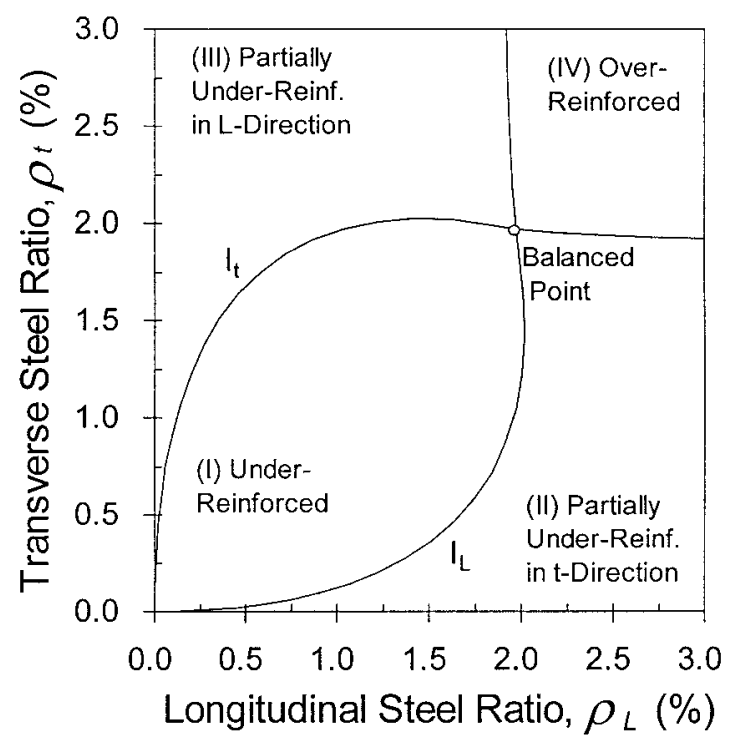

FIG. 2. Failure Mode Diagram $\varepsilon_{c u}=-0.0035$; similarly, curve $I_{t}$ corresponds to $\varepsilon_{t}=\varepsilon_{t y}$ when $\varepsilon_{d s}=-0.0035$. Hence, the balanced point in Fig. 2 (i.e., the intersection of curves $I_{L}$ and $I_{t}$ ) represents the case of $\varepsilon_{L}=\varepsilon_{L y}$ and $\varepsilon_{t}=\varepsilon_{t y}$ when $\varepsilon_{d s}=-0.0035$. The procedure for constructing $I_{L}$ is detailed in the following, and $I_{t}$ can be constructed analogously:

1. Conditions given: $\varepsilon_{d s}=-0.0035, \varepsilon_{d}=\varepsilon_{d s} / 2$, and $\varepsilon_{L}=\varepsilon_{L y}$ (i.e., $f_{L}=f_{L y}$ ).

2. Select an angle $\alpha$ ranging from $0^{\circ}$ to $90^{\circ}$.

3. First calculate $\varepsilon_{t}$ from (8), and then calculate $\varepsilon_{r}$ from (7).

4. Calculate $f_{t}$. If $\varepsilon_{t}<\varepsilon_{t y}$, then $f_{t}=E_{s} \varepsilon_{t}$; otherwise $f_{t}=f_{t y}$.

5. Calculate $\beta$ from (15).

6. Obtain $t_{d}$ by solving the quadratic equation that is obtained from

$$
\varepsilon_{d s}=-\frac{2 t_{d}\left(p_{c}-4 \xi t_{d}\right)\left(\varepsilon_{L}-\varepsilon_{d}\right)}{A_{c}-0.5 p_{c} t_{d}+\xi t_{d}^{2}} \cos ^{2} \alpha
$$

This equation was derived by substituting (18) and (19) into (22).

7. Calculate $\sigma_{d}$ using (16), where $k_{1}=35 / 48$, being obtained by the substitution of $\varepsilon_{c 0}=-0.002$ and $\varepsilon_{d s}=-0.0035$ into (17).

8. Calculate $\rho_{L}$ and $\rho_{t}$ from (1) and (2), respectively. These two values correspond to a point on curve $I_{L}$.

9. Vary the angle $\alpha$ incrementally and repeat Steps $2-8$ to allow generation of a series of points to plot curve $I_{L}$.

\section{NORMALIZED FAILURE MODE DIAGRAM}

\section{Normalized Steel Ratios}

The reinforcement ratios $\rho_{L}$ and $\rho_{t}$ defined in (4) and (5) depend on the thickness $t_{d}$. Therefore, they are not convenient for use in design. Instead another set of reinforcement ratios $\delta_{L}$ and $\delta_{t}$ is introduced as follows:

$$
\begin{gathered}
\delta_{L}=\frac{A_{L}}{A_{c}} \\
\delta_{t}=\frac{A_{t} p_{c}}{s A_{c}}
\end{gathered}
$$

Using (1), (2), (4), and (5), then (27) and (28) can be expressed, respectively, as

$$
\begin{gathered}
\delta_{L}=-\frac{\sigma_{d}}{f_{L}} \frac{p_{0} t_{d}}{A_{c}} \cos ^{2} \alpha \\
\delta_{t}=-\frac{\sigma_{d}}{f_{t}} \frac{p_{c} t_{d}}{A_{c}} \sin ^{2} \alpha
\end{gathered}
$$

By investigating the procedures for constructing failure boundaries $I_{L}$ and $I_{t}$ outlined above, it can be found that $\beta$ is independent of $f_{c}^{\prime}$. Hence, $\sigma_{d}$ is linearly related to $f_{c}^{\prime}$ according to (16). To let curves $I_{L}$ and $I_{t}$ be independent of $f_{c}^{\prime}$, one can define another set of reinforcement ratios as follows:

$$
\begin{aligned}
& \eta_{L}=\frac{f_{y}}{f_{c}^{\prime}} \delta_{L}=-\frac{\sigma_{d} / f_{c}^{\prime}}{f_{L} / f_{y}}\left(\frac{p_{0} t_{d}}{A_{c}}\right) \cos ^{2} \alpha \\
& \eta_{t}=\frac{f_{y}}{f_{c}^{\prime}} \delta_{t}=-\frac{\sigma_{d} / f_{c}^{\prime}}{f_{t} / f_{y}}\left(\frac{p_{c} t_{d}}{A_{c}}\right) \sin ^{2} \alpha
\end{aligned}
$$

Notice that $f_{y}$ is taken as the average of $f_{L y}$ and $f_{t y}$ and is used in defining $\eta_{L}$ and $\eta_{t}$ to let them remain nondimensional. Hereafter, $\eta_{L}$ and $\eta_{t}$ will be referred to as normalized longitudinal steel and transverse steel ratios, respectively.

For a rectangular solid or thin-walled section, let its smaller dimension be $x$ and its larger dimension be $y$, and define $n=$ $y / x$ as the aspect ratio. Substituting $p_{c}=2(x+n x)$ and $A_{c}=$ 
$n x^{2}$ into (26) and solving for $t_{d}$, one can find that $t_{d}$ is a function of $n$ and is proportional to $x$. Using this fact and (19), it can be shown that the terms in parentheses in (31) and (32) depend only on $n$ and not on the dimensions of the section.

On the basis of the above discussion, if $\alpha, f_{y}$ (or $\varepsilon_{y} \equiv f_{y} / E_{s}$ ), and $n$ are fixed, then the values of $\eta_{L}$ and $\eta_{t}$ [determined using (31) and (32) by substituting the values of $\sigma_{d}, t_{d}, f_{L}, f_{t}, p_{0}$, etc., obtained from the procedure used in constructing the failure boundaries] would be independent of the dimensions of the section and $f_{c}^{\prime}$. That is, the failure mode diagram constructed on the $\eta_{L}-\eta_{t}$-plane would be the same regardless of the dimensions of the sections and $f_{c}^{\prime}$. The effects of $f_{y}$ (or $\varepsilon_{y}$ ) and $n$ are discussed below.

\section{Effects of Yield Strength of Steel and Section Aspect Ratio}

To investigate the effect of $f_{y}$ (or $\varepsilon_{y}$ ) on the failure mode diagram, define $a=-\varepsilon_{y} / \varepsilon_{c u}$. Recall that this study uses $\varepsilon_{c u}=$ -0.0035 . For the commonly used steel grades 40,50 , and 60 , the yield strengths are 274.68, 343.35, and 412.02 $\mathrm{MPa}$, respectively. Because $E_{s}=200 \mathrm{GPa}$, the values of the parameter $a$ equal $0.4,0.5$, and 0.6 for grades 40,50 , and 60 , respectively. Assuming that $n=1.5$, the failure mode diagrams on the $\eta_{L}-\eta_{t}$-plane for $a=0.4,0.5$, and 0.6 are depicted in Fig. 3 . It can be seen that even though the size of each failure mode region is changed significantly, the shape remains similar.

Fig. 4 shows the effect of the section aspect ratio $n$ on the failure mode diagram. Clearly, the effect is insignificant.

\section{Reinforcement Indices and Normalized Failure Mode Diagram}

Because the shapes of the failure mode diagrams for different values of $(a, n)$ are similar, as can be seen from Figs. 3 and 4 , it is possible to unify these failure mode diagrams through the introduction of the following reinforcement indices:

$$
\begin{aligned}
\phi_{L} & =\frac{\eta_{L}}{\eta_{L b}} \\
\phi_{t} & =\frac{\eta_{t}}{\eta_{t b}}
\end{aligned}
$$

where $\eta_{L b}=\eta_{t b}=$ normalized reinforcement ratios associated

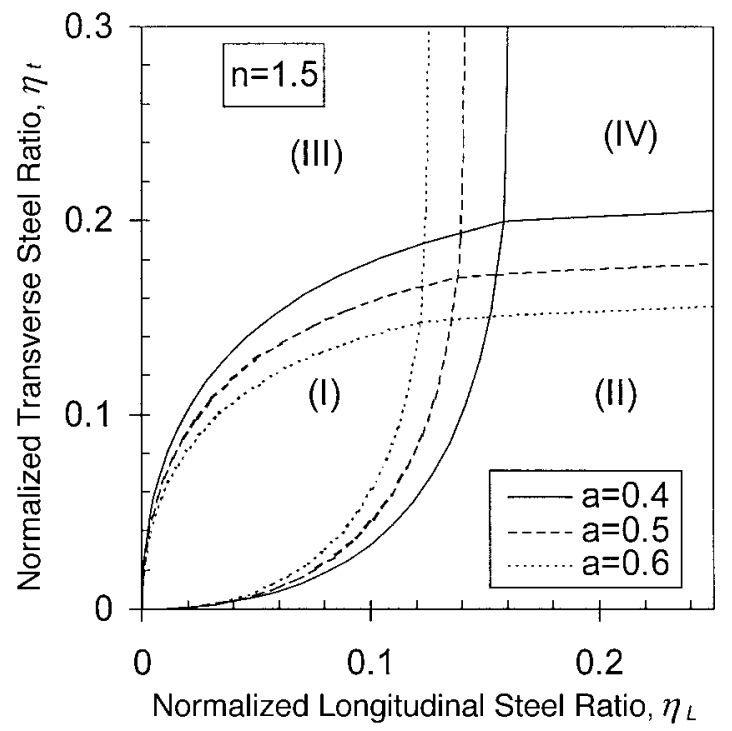

FIG. 3. Effect of Yield Strain $\left(a=-\varepsilon_{y} / \varepsilon_{c u}\right)$

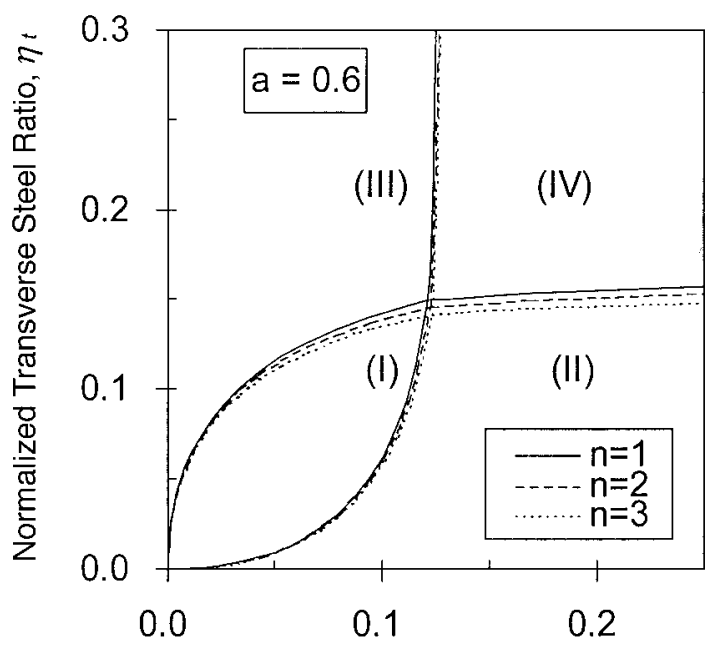

Normalized Longitudinal Steel Ratio, $\eta_{L}$

FIG. 4. Effect of Aspect Ratio $n$

with the balanced point. The failure mode diagram constructed on the $\phi_{L}-\phi_{t}$-plane is hereafter referred to as the normalized failure mode diagram. Figs. 5 and 6 show the normalized failure mode diagrams corresponding to Figs. 3 and 4, respectively. As can be clearly seen, all the normalized failure diagrams are almost identical.

In (33) and (34), $\eta_{L b}$ and $\eta_{t b}$ are functions of $a$ and $n$. Their relations can be determined in a similar way to that used in obtaining $I_{L}$ and $I_{t}$. The conditions associated with the balanced point are that $\varepsilon_{L}=\varepsilon_{t}=\varepsilon_{y}$ (i.e., $f_{L}=f_{t}=f_{y}$ ) and $\varepsilon_{d s}=-0.0035$. Hence, $\alpha=45^{\circ}$ from (8), and $\varepsilon_{r}=2 \varepsilon_{y}-0.5 \varepsilon_{d s}$ from (7) and (13). First, use the above conditions and follow Steps 5-7 in the procedure for constructing the failure boundaries to yield $t_{d}$ and $\sigma_{d}$. Then, use the expressions after the second equal sign of (31) and (32) to determine $\eta_{L b}$ and $\eta_{t b}$. Fig. 7 shows how $\eta_{L b}$ and $\eta_{t b}$ depend on $a$ and $n$; clearly, the effect of $n$ is minor. Once the values of $a$ and $n$ are known, the values of $\eta_{L b}$ and $\eta_{t b}$ can be read directly from this figure. To facilitate calculation, the following approximate formulas, obtained using curve fitting with respect to $n=1.5$, are proposed:

$\eta_{L b}=\frac{76}{200+f_{y}} \quad\left(f_{y}\right.$ in $\left.\mathrm{MPa}\right) \quad$ or $\quad \eta_{L b}=\frac{11,000}{30,000+f_{y}} \quad\left(f_{y}\right.$ in psi $)$

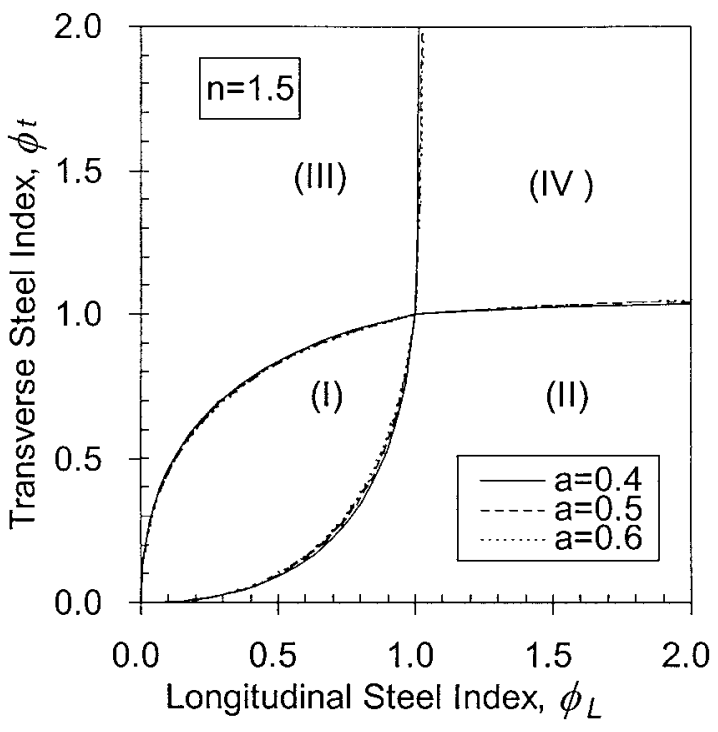

FIG. 5. Normalized Failure Mode Diagram for Different $a$ (Steel Grades) 


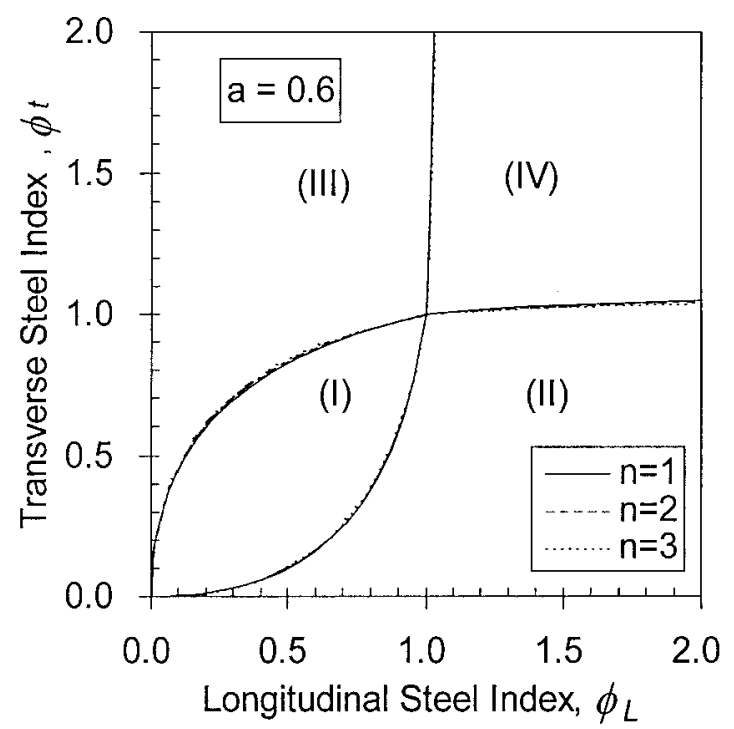

FIG. 6. Normalized Failure Mode Diagram for Different $n$ (Aspect Ratios)

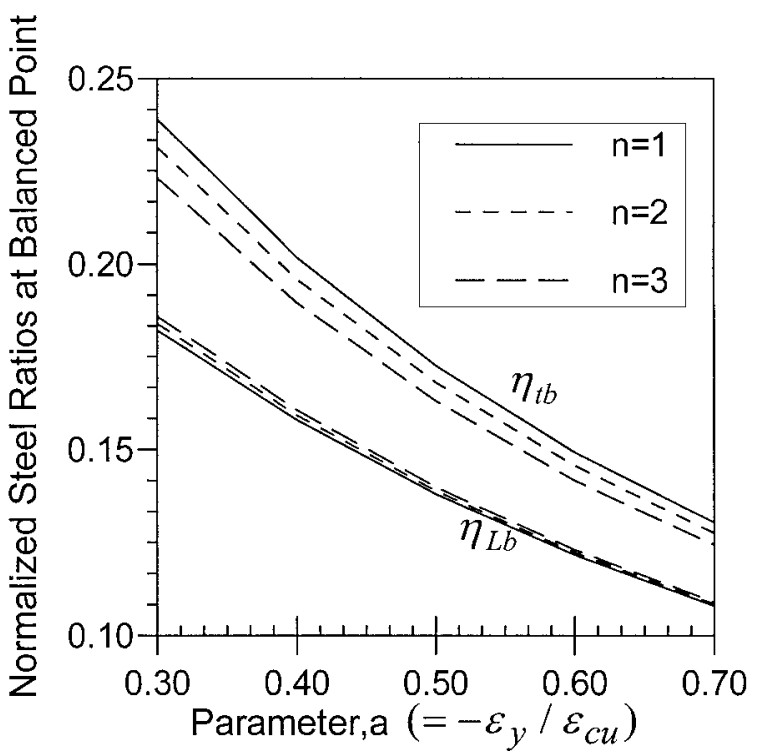

FIG. 7. Normalized Reinforcement Ratios at Balanced Point

$$
\eta_{t b}=\frac{76}{100+f_{y}}\left(f_{y} \text { in MPa }\right) \quad \text { or } \quad \eta_{t b}=\frac{11,000}{15,000+f_{y}} \quad\left(f_{y} \text { in psi }\right)
$$

\section{Determination of Failure Mode Using Normalized Failure Mode Diagram}

Given a reinforced concrete rectangular member, the torsional failure mode can be determined using the proposed normalized failure mode diagram as follows. First, calculate $\delta_{L}$ and $\delta_{t}$ using (27) and (28); then substitute these into the expressions after the first equal sign of (31) and (32) to yield $\eta_{L}$ and $\eta_{t}$. Next, obtain $\eta_{L b}$ and $\eta_{t b}$ from (35) and (36). Finally, evaluate $\phi_{L}$ and $\phi_{t}$ using (33) and (34) and refer to Fig. 5 (or Fig. 6) to determine the failure mode.

\section{STRENGTH CONTOUR DIAGRAM}

In developing the failure mode diagram, failure is assumed to occur when $\varepsilon_{d s}=\varepsilon_{c u}=-0.0035$. Hence, the torsional strength discussed below also represents the strength corresponding to this strain. Typical torque-twist curves can be found in Hsu (1993) and Lee (1998), indicating that the torque corresponding to $\varepsilon_{d s}=-0.0035$ is only slightly less than the maximum torque (the actual strength). This justifies the use of the torque corresponding to $\varepsilon_{d s}=-0.0035$ as the torsional strength.

\section{Torsional Strength for Underreinforced Case}

For the underreinforced case [i.e., failure mode (I)], the torsional strength can be obtained following the steps outlined as follows:

1. Conditions given: $\varepsilon_{d s}=-0.0035, \varepsilon_{d}=\varepsilon_{d s} / 2, \varepsilon_{L}=\varepsilon_{L y}$ (i.e., $f_{L}=f_{L y}$ ), and $\varepsilon_{t}=\varepsilon_{t y}$ (i.e., $f_{t}=f_{t y}$ ).

2. Assume the initial wall thickness $t_{d}=0.75 A_{c} / p_{c}$.

3. Calculate $A_{0}$ and $p_{0}$ according to (18) and (19), respectively.

4. Calculate the angle of inclination of the concrete struts using $\alpha=\tan ^{-1} \sqrt{f_{t y} A_{t} p_{0} /\left(f_{L y} s A_{L}\right)}$, which can be obtained by means of dividing (2) by (1) knowing that $f_{L}=f_{L y}$ and $f_{t}=f_{t y}$.

5. Calculate $\sigma_{d}$ using $\sigma_{d}=-A_{L} f_{L y} /\left(p_{0} t_{d}\right)-A_{t} f_{t y} /\left(s t_{d}\right)$, which can be derived by adding (1) and (2) together.

6. Update the wall thickness by $t_{d 1}=-A_{t} f_{t y} /\left(\sigma_{d} s \sin ^{2} \alpha\right)$, which can be obtained from rearranging (2).

7. Check whether the convergence criterion, $\left|t_{d 1}-t_{d}\right| / t_{d 1} \leq$ $e_{1}$, is satisfied, where $e_{1}$ is a preset tolerance; $e_{1}=0.01$ is adopted in this study. If convergence is achieved, go the next step. Otherwise, let $t_{d}=0.5\left(t_{d}+t_{d 1}\right)$ and go back to Step 3 for the next iteration.

8. Calculate the torsional strength using (20).

\section{Torsional Strength for Partially Underreinforced or Overreinforced Cases}

For the partially underreinforced or overreinforced cases including failure modes (II), (III), and (IV), the torsional strength can be calculated as follows:

1. Conditions given: $\varepsilon_{d s}=-0.0035$ and $\varepsilon_{d}=\varepsilon_{d s} / 2$.

2. Assume the initial wall thickness $t_{d}=0.75 A_{c} / p_{c}$ and the initial softening coefficient $\beta=0.5$.

3. Calculate $A_{0}$ and $p_{0}$ according to (18) and (19), respectively.

4. Calculate $\sigma_{d}$ according to (16), where $k_{1}=35 / 48$.

5. Calculate $\varepsilon_{L}$ and $\varepsilon_{t}$ as follows. Assume that $f_{L}=f_{L y}$ in (23), from which

$$
\varepsilon_{L}=\left(1+\frac{A_{0} \sigma_{d}}{A_{L} f_{L y}}\right) \varepsilon_{d}
$$

If $\varepsilon_{L} \geq \varepsilon_{L y}$, the assumption is valid. Otherwise, calculate $\varepsilon_{L}$ by means of

$$
\varepsilon_{L}=\frac{\varepsilon_{d}}{2}+\sqrt{\frac{\varepsilon_{d}^{2}}{4}+\frac{\sigma_{d} A_{0} \varepsilon_{d}}{E_{s} A_{L}}}
$$

which can be derived by substituting $f_{L}=E_{s} \varepsilon_{L}$ into (23). Equations, similar to (37) and (38), for calculating $\varepsilon_{t}$ can be derived from (25).

6. Calculate $f_{L}$ and $f_{t}$ using $f_{L}=E_{s} \varepsilon_{L} \leq f_{L y}$ and $f_{t}=E_{s} \varepsilon_{t} \leq$ $f_{t y}$, respectively.

7. Calculate $\varepsilon_{r}$ from (7).

8. Calculate the angle of inclination using $\alpha=\tan ^{-1}$ $\sqrt{f_{t} A_{t} p_{0} /\left(f_{L} s A_{L}\right)}$, which can be obtained by dividing (2) by (1).

9. Update the wall thickness by $t_{d 1}=-\left(A_{L} f_{L} / p_{0}+A_{t} f_{t} /\right.$ $s) / \sigma_{d}$, which is obtained by adding (1) and (2) together.

10. Update the softening coefficient $\beta$ according to (15).

11. Check the following convergence criteria, $\left|t_{d 1}-t_{d}\right| / t_{d 1}$ 
$\leq e_{1}$ and $\left|\beta_{1}-\beta\right| / \beta_{1} \leq e_{2}$, where $t_{d 1}$ and $\beta_{1}$ are the updated values. Also, $e_{1}=e_{2}=0.01$. If they are satisfied, go to the next step. Otherwise, let $t_{d}=0.5\left(t_{d}+\right.$ $\left.t_{d 1}\right), \beta=0.5\left(\beta+\beta_{1}\right)$, and then go to Step 3 to start the next iteration.

12. Calculate the torsional strength using (20).

Notice that the above procedure is also applicable for the underreinforced case, although it requires more iterations to achieve convergence than the previous procedure.

\section{Strength Contour Diagram}

The purpose here is to develop a diagram on the $\phi_{L}-\phi_{t^{-}}$ plane, from which the torsional strength can be obtained directly without the above tedious calculations. Fig. 8 shows such a strength contour diagram for the cases of $a=0.4$ and 0.6. The contour represents the relative strength with respect to the balanced point, whose strength is hereafter denoted by $M_{x u b}$. For example, the strength read from Fig. 8 corresponding to $\left(\phi_{L}, \phi_{t}\right)=(0.6,0.5)$ would be about $0.6 M_{x u b}$. Therefore, if $M_{x u b}$ is known, then the torsional strength $M_{x u}$ can be obtained immediately. The construction of the strength contour diagram and the evaluation of $M_{x u b}$ are detailed as follows.

First, define an index called the torsional strength index as follows:

$$
\phi_{s}=\frac{M_{x u}}{M_{x u b}}
$$

The procedures for calculating the torsional strength $M_{x u}$ are described in the above two subsections. $M_{x u b}$ can be readily obtained after the determination of $\eta_{L b}$ and $\eta_{t b}$ in (33) and (34), because the calculation of $\eta_{L b}$ and $\eta_{t b}$ requires that $\alpha, t_{d}$, and $\sigma_{d}$ be determined first. Once these values are known, the corresponding torsional strength can be evaluated using (20).

\section{Effect of Yield Strength of Steel and Section Aspect Ratio}

Note that $\phi_{s}$ is independent of the dimensions of the section but is dependent on the aspect ratio $n$ and $\varepsilon_{y}$ (or $f_{y}$ ). For example, for a fixed aspect ratio $n=1.5$, the contour of $\phi_{s}$ (i.e., the strength contour) is shown in Fig. 8 for steel of grades 40 $(a=0.4)$ and $60(a=0.6)$. Clearly, the effect of steel grade is minor except for the overreinforced case. Similar contours can

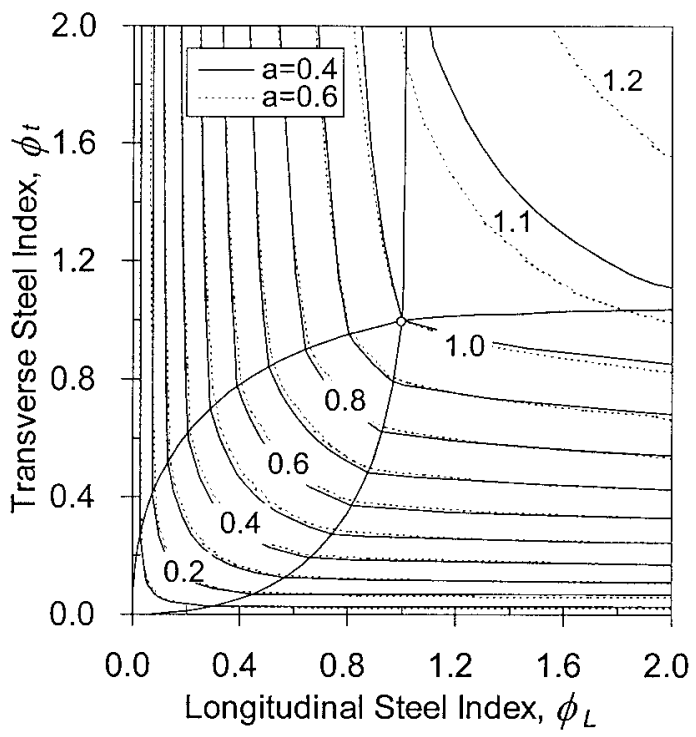

FIG. 8. Strength Contour Diagram

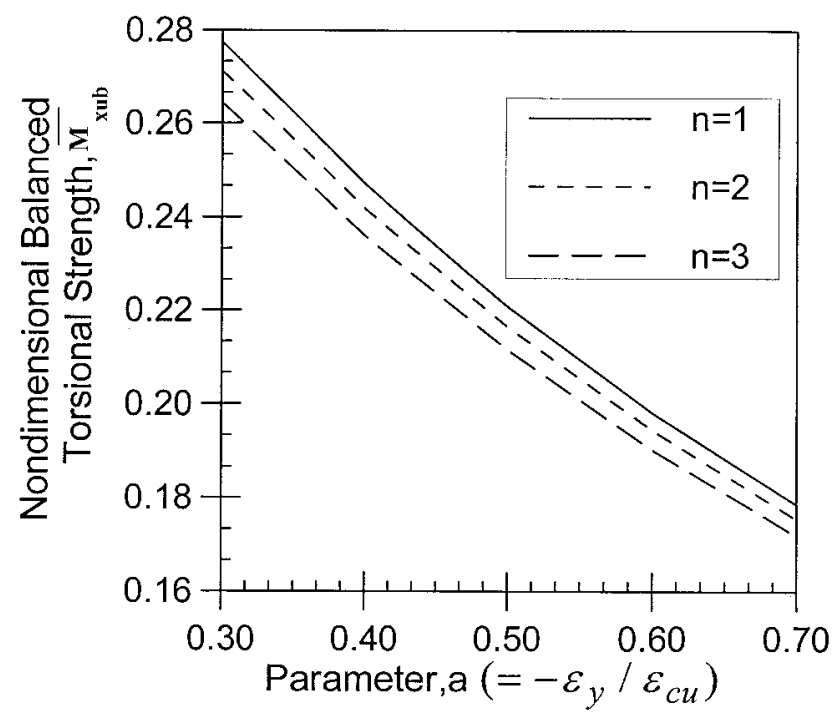

FIG. 9. Nondimensional Balanced Torsional Strength

be constructed, although not shown here, indicating that the effect of the aspect ratio $n$ is also insignificant. Therefore, because the strength contour diagram of Fig. 8 is constructed for the case of $n=1.5$, it can be conveniently used for design of typical sections.

\section{Formula for Determining Balanced Torsional Strength}

The torsional strength $M_{x u b}$ associated with the balanced point can be determined as discussed above. However, it is not convenient for design. A more convenient method is proposed here. To this end, a nondimensional balanced torsional strength is introduced as follows:

$$
\bar{M}_{x u b}=\frac{M_{x u b} p_{c}}{f_{c}^{\prime} A_{c}^{2}}
$$

It can be shown that $\bar{M}_{x u b}$ is dependent on $\varepsilon_{y}$ and $n$, but it is independent of the dimensions of the section and of $f_{c}^{\prime}$. With the definition given in (40), the relationship between $\bar{M}_{x u b}, \varepsilon_{y}$, and $n$ can be obtained, which is depicted in Fig. 9. For design purposes, the following approximate formulas are proposed:

$$
\begin{aligned}
& \bar{M}_{x u b}=\frac{140}{300+f_{y}} \quad\left(f_{y} \text { in } \mathrm{MPa}\right) \\
& \text { or } \quad \bar{M}_{x u b}=\frac{20,000}{42,000+f_{y}} \quad\left(f_{y} \text { in psi }\right)
\end{aligned}
$$

These are obtained by curve fitting to the data corresponding to $n=1.5$.

\section{Angle of Inclination of Concrete Struts}

In the construction of the failure mode diagram and the strength contour diagram, the angle of inclination of the concrete struts is also available. Fig. 10 provides this information only for the underreinforced case as it is the most desirable failure mode. Limiting the angle of inclination to a certain range is useful for crack control (Hsu 1993). Usually, it is required that $\tan ^{-1}(3 / 5)=30.9^{\circ}<\alpha<\tan ^{-1}(5 / 3)=59.1^{\circ}$.

\section{APPLICATION}

Table 1 lists the dimensions $x$ and $y$ and material properties for a total of 39 specimens with rectangular sections that were reported in Hsu (1968) [(see also Wang and Hsu (1997)]. For each specimen, two methods are used to determine the torsional strength and the associated failure mode. The first 


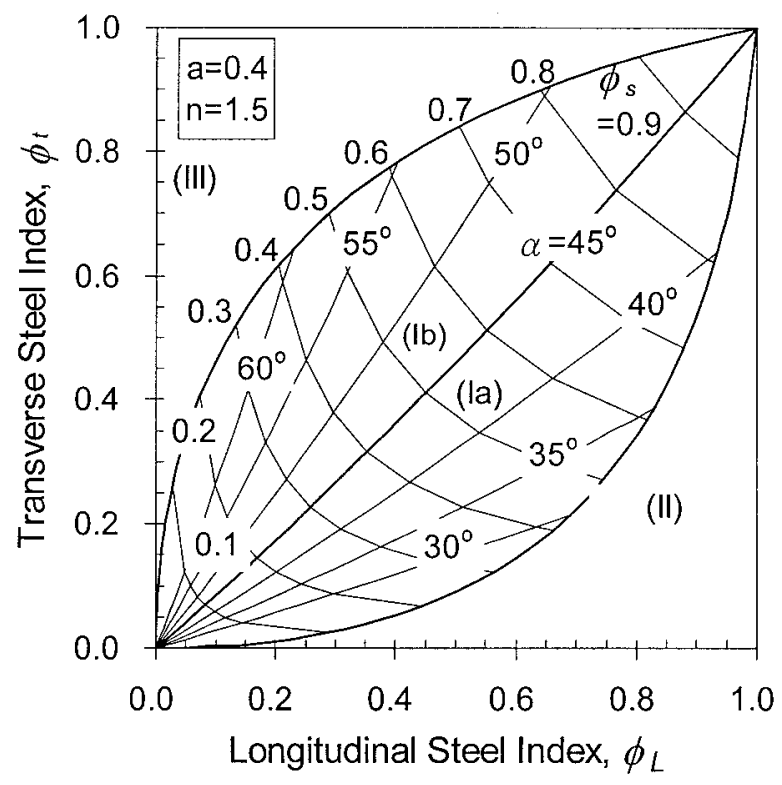

FIG. 10. Contour of Angle of Inclination of Concrete Struts method is based on the proposed design charts, and the second method solves the softened truss model directly. Note again that the average yield strength is adopted for both the longitudinal steel and transverse steel when the design charts are employed, although their actual strengths are used in the softened truss model. In addition, unless otherwise mentioned, all results from the design charts correspond to $a=0.4$. The predicted failure mode and torsional strength for each specimen obtained using the above two methods are given in Table 2, where the measured (experimental) strength from Hsu (1968) is also listed. To demonstrate the use of the proposed design charts, a detailed calculation for specimen B1 is given in Appendix I, and how to apply the design charts to design is also briefly discussed.

Note that the strengths for specimens B6, B10, M5, M6, C5, and C6 cannot be obtained using the strength contour diagram (Fig. 8) because the diagram is plotted up to the values of $\phi_{L}$ and $\phi_{t}$ of 2. Also, for specimens B5 and C4 with $1<$ $\phi_{s}<1.1$, the predicted strengths are obtained corresponding to $a=0.6$. As can be seen from Table 2, the failure modes predicted using the proposed design charts and the softened truss model are the same except for specimen M2. The exception is due to the fact that specimen M2 is the second largest

TABLE 1. Section and Material Properties of Torsional Members

\begin{tabular}{|c|c|c|c|c|c|c|c|}
\hline \multirow[b]{2}{*}{$\begin{array}{c}\text { Specimen } \\
\text { (1) }\end{array}$} & \multirow[b]{2}{*}{$\begin{array}{c}x \\
(\mathrm{~cm}) \\
(2)\end{array}$} & \multirow[b]{2}{*}{$\begin{array}{c}y \\
(\mathrm{~cm}) \\
(3)\end{array}$} & \multirow[b]{2}{*}{$\begin{array}{c}f_{c}^{\prime} \\
(\mathrm{MPa}) \\
(4)\end{array}$} & \multirow[b]{2}{*}{$\begin{array}{c}f_{L y} \\
(\mathrm{MPa}) \\
(5)\end{array}$} & \multirow[b]{2}{*}{$\begin{array}{c}f_{t y} \\
(\mathrm{MPa}) \\
(6)\end{array}$} & \multicolumn{2}{|c|}{ Reinforcement } \\
\hline & & & & & & $\begin{array}{l}\text { Longitudinal } \\
(7)\end{array}$ & $\begin{array}{c}\text { Transverse } \\
(\mathrm{cm}) \\
(8)\end{array}$ \\
\hline B1 & 25.4 & 38.1 & 27.58 & 313.71 & 341.29 & $4 \# 4$ & $\# 3$ at 15.24 \\
\hline $\mathrm{B} 2$ & 25.4 & 38.1 & 28.61 & 316.47 & 319.92 & $4 \# 5$ & $\# 4$ at 18.11 \\
\hline B3 & 25.4 & 38.1 & 28.06 & 327.50 & 319.92 & $4 \# 6$ & $\# 4$ at 12.70 \\
\hline B4 & 25.4 & 38.1 & 30.54 & 319.92 & 323.36 & $4 \# 7$ & $\# 4$ at 9.22 \\
\hline B5 & 25.4 & 38.1 & 29.03 & 332.33 & 321.30 & $4 \# 8$ & $\# 4$ at 6.99 \\
\hline B6 & 25.4 & 38.1 & 28.82 & 331.64 & 322.67 & $4 \# 9$ & $\# 4$ at 5.72 \\
\hline B7 & 25.4 & 38.1 & 25.99 & 319.92 & 318.54 & $4 \# 4$ & $\# 4$ at 12.70 \\
\hline B8 & 25.4 & 38.1 & 26.75 & 321.99 & 319.92 & $4 \# 4$ & $\# 4$ at 5.72 \\
\hline B9 & 25.4 & 38.1 & 28.82 & 319.23 & 342.67 & $4 \# 6$ & $\# 4$ at 15.24 \\
\hline B10 & 25.4 & 38.1 & 26.48 & 334.40 & 341.98 & $4 \# 9$ & $\# 4$ at 15.24 \\
\hline D1 & 25.4 & 38.1 & 26.61 & 333.02 & 337.84 & $4 \# 4$ & $\# 3$ at 15.24 \\
\hline D2 & 25.4 & 38.1 & 25.58 & 322.67 & 330.95 & $4 \# 5$ & $\# 4$ at 18.11 \\
\hline D3 & 25.4 & 38.1 & 28.41 & 341.29 & 333.02 & $4 \# 6$ & $\# 4$ at 12.70 \\
\hline D4 & 25.4 & 38.1 & 30.61 & 330.26 & 333.02 & $4 \# 7$ & $\# 4$ at 9.22 \\
\hline M1 & 25.4 & 38.1 & 29.85 & 326.12 & 353.01 & $4 \# 5$ & $\# 3$ at 14.94 \\
\hline M2 & 25.4 & 38.1 & 30.54 & 328.88 & 357.15 & $4 \# 6$ & $\# 3$ at 10.49 \\
\hline M3 & 25.4 & 38.1 & 26.75 & 321.99 & 326.12 & $4 \# 7$ & $\# 4$ at 13.97 \\
\hline M4 & 25.4 & 38.1 & 26.54 & 318.54 & 326.81 & $4 \# 8$ & $\# 4$ at 10.49 \\
\hline M5 & 25.4 & 38.1 & 27.99 & 335.09 & 330.95 & $4 \# 9$ & $\# 4$ at 8.26 \\
\hline M6 & 25.4 & 38.1 & 29.37 & 317.85 & 340.60 & $6 \# 8$ & $\# 4$ at 6.99 \\
\hline $\mathrm{I} 2$ & 25.4 & 38.1 & 45.23 & 325.43 & 348.87 & $4 \# 5$ & $\# 3$ at 9.86 \\
\hline I3 & 25.4 & 38.1 & 44.75 & 343.36 & 333.71 & $4 \# 6$ & $\# 4$ at 12.70 \\
\hline I4 & 25.4 & 38.1 & 44.95 & 315.09 & 326.12 & $4 \# 7$ & $\# 4$ at 9.22 \\
\hline I5 & 25.4 & 38.1 & 45.02 & 310.26 & 325.43 & $4 \# 8$ & $\# 4$ at 6.99 \\
\hline I6 & 25.4 & 38.1 & 45.78 & 325.43 & 328.88 & $4 \# 9$ & $\# 4$ at 5.72 \\
\hline G1 & 25.4 & 50.8 & 29.79 & 321.99 & 339.22 & 4\#4 & $\# 3$ at 18.75 \\
\hline $\mathrm{G} 2$ & 25.4 & 50.8 & 30.89 & 322.67 & 333.71 & $4 \# 5$ & $\# 3$ at 12.07 \\
\hline G3 & 25.4 & 50.8 & 26.82 & 338.53 & 327.50 & $4 \# 6$ & $\# 4$ at 15.57 \\
\hline G4 & 25.4 & 50.8 & 28.27 & 325.43 & 341.98 & $4 \# 7$ & $\# 4$ at 11.43 \\
\hline G5 & 25.4 & 50.8 & 26.89 & 330.95 & 327.50 & $4 \# 8$ & $\# 4$ at 8.59 \\
\hline G6 & 25.4 & 50.8 & 29.92 & 334.40 & 349.56 & $6 \# 4$ & $\# 4$ at 12.70 \\
\hline G7 & 25.4 & 50.8 & 30.96 & 319.23 & 322.67 & $6 \# 5$ & $\# 4$ at 14.61 \\
\hline G8 & 25.4 & 50.8 & 28.34 & 321.99 & 328.88 & $6 \# 6$ & $\# 4$ at 10.49 \\
\hline $\mathrm{C} 1$ & 25.4 & 25.4 & 27.03 & 341.29 & 341.29 & $4 \# 3$ & $\# 3$ at 21.59 \\
\hline $\mathrm{C} 2$ & 25.4 & 25.4 & 26.54 & 334.40 & 344.74 & 4\#4 & $\# 3$ at 11.76 \\
\hline $\mathrm{C} 3$ & 25.4 & 25.4 & 26.89 & 330.95 & 329.57 & $4 \# 5$ & $\# 4$ at 13.97 \\
\hline $\mathrm{C} 4$ & 25.4 & 25.4 & 27.17 & 336.46 & 327.50 & $4 \# 6$ & $\# 4$ at 9.86 \\
\hline $\mathrm{C} 5$ & 25.4 & 25.4 & 27.23 & 328.19 & 328.88 & $4 \# 7$ & $\# 4$ at 7.32 \\
\hline C6 & 25.4 & 25.4 & 27.58 & 315.78 & 327.50 & $4 \# 8$ & $\# 4$ at 5.41 \\
\hline
\end{tabular}


TABLE 2. Comparison of Experimental and Predicted Torsional Strengths and Predicted Failure Modes

\begin{tabular}{|c|c|c|c|c|c|c|c|c|c|c|c|}
\hline \multirow[b]{2}{*}{$\begin{array}{c}\text { Specimen } \\
(1)\end{array}$} & \multirow[b]{2}{*}{$\begin{array}{c}M_{\exp }{ }^{\mathrm{a}} \\
(\mathrm{kN} \cdot \mathrm{m}) \\
(2)\end{array}$} & \multirow[b]{2}{*}{$\begin{array}{l}\phi_{L} \\
(3)\end{array}$} & \multirow[b]{2}{*}{$\begin{array}{r}\phi_{t} \\
(4)\end{array}$} & \multirow[b]{2}{*}{$\begin{array}{c}M_{x u b} \\
(\mathrm{kN} \cdot \mathrm{m}) \\
(5)\end{array}$} & \multicolumn{3}{|c|}{ From Design Charts } & \multicolumn{2}{|c|}{ From STM ${ }^{\mathrm{b}}$} & \multirow[b]{2}{*}{$\begin{array}{l}\frac{(7)}{(9)} \\
(11)\end{array}$} & \multirow[b]{2}{*}{$\begin{array}{l}\frac{(9)}{(2)} \\
(12)\end{array}$} \\
\hline & & & & & $\begin{array}{l}\phi_{s} \\
(6) \\
\end{array}$ & $\begin{array}{c}M_{x u} \\
(\mathrm{kN} \cdot \mathrm{m}) \\
(7)\end{array}$ & $\begin{array}{c}\text { Failure } \\
\text { mode } \\
(8)\end{array}$ & $\begin{array}{c}M_{x u} \\
(\mathrm{kN} \cdot \mathrm{m}) \\
(9)\end{array}$ & $\begin{array}{c}\text { Failure } \\
\text { mode } \\
(10)\end{array}$ & & \\
\hline B1 & 22.26 & 0.43 & 0.41 & 45.4 & 0.48 & 21.78 & I & 22.39 & I & 0.97 & 1.01 \\
\hline B2 & 29.26 & 0.62 & 0.56 & 47.8 & 0.65 & 31.06 & I & 31.37 & I & 0.99 & 1.07 \\
\hline B3 & 37.51 & 0.94 & 0.84 & 46.4 & 0.91 & 42.27 & I & 42.96 & I & 0.98 & 1.15 \\
\hline B4 & 47.34 & 1.16 & 1.05 & 50.7 & 1.02 & 51.73 & IV & 53.08 & IV & 0.97 & 1.12 \\
\hline B5 & 56.15 & 1.63 & 1.50 & 47.8 & 1.15 & 54.98 & IV & 55.19 & IV & 1.00 & 0.98 \\
\hline B6 & 61.69 & 2.10 & 1.85 & 47.4 & - & - & IV & 57.97 & IV & - & 0.94 \\
\hline B7 & 26.89 & 0.44 & 0.89 & 43.3 & 0.65 & 28.16 & III & 28.72 & III & 0.98 & 1.07 \\
\hline B8 & 32.54 & 0.43 & 1.93 & 44.5 & 0.68 & 30.24 & III & 31.30 & III & 0.97 & 0.96 \\
\hline B9 & 29.83 & 0.94 & 0.71 & 47.2 & 0.86 & 40.55 & I & 40.60 & I & 1.00 & 1.36 \\
\hline B10 & 34.35 & 2.41 & 0.80 & 42.8 & - & - & II & 43.37 & II & - & 1.26 \\
\hline D1 & 22.37 & 0.47 & 0.44 & 43.2 & 0.52 & 22.48 & I & 22.50 & I & 1.00 & 1.01 \\
\hline D2 & 27.68 & 0.72 & 0.66 & 42.1 & 0.74 & 31.18 & I & 31.49 & I & 0.99 & 1.14 \\
\hline D3 & 40.22 & 0.99 & 0.89 & 46.0 & 0.94 & 43.27 & II & 44.13 & II & 0.98 & 1.10 \\
\hline D4 & 47.90 & 1.22 & 1.11 & 50.0 & 1.03 & 51.53 & IV & 53.16 & IV & 0.97 & 1.11 \\
\hline M1 & 30.39 & 0.66 & 0.41 & 48.2 & 0.57 & 27.46 & I & 28.23 & I & 0.97 & 0.93 \\
\hline M2 & 40.56 & 0.95 & 0.58 & 49.0 & 0.78 & 38.24 & II & 38.57 & I & 0.99 & 0.95 \\
\hline M3 & 43.84 & 1.34 & 0.80 & 44.3 & 0.94 & 41.60 & II & 42.33 & II & 0.98 & 0.97 \\
\hline M4 & 49.60 & 1.75 & 1.07 & 44.0 & 1.06 & 46.64 & IV & 48.70 & IV & 0.96 & 0.98 \\
\hline M5 & 55.70 & 2.22 & 1.36 & 45.6 & - & - & IV & 53.94 & IV & - & 0.97 \\
\hline M6 & 60.10 & 2.45 & 1.51 & 48.2 & - & - & IV & 58.27 & IV & - & 0.97 \\
\hline I2 & 36.04 & 0.43 & 0.41 & 73.3 & 0.48 & 35.18 & I & 36.00 & I & 0.98 & 1.00 \\
\hline I3 & 45.64 & 0.63 & 0.57 & 72.4 & 0.65 & 47.03 & I & 48.21 & I & 0.98 & 1.06 \\
\hline I4 & 58.07 & 0.78 & 0.71 & 74.8 & 0.79 & 59.07 & I & 59.79 & I & 0.99 & 1.03 \\
\hline I5 & 70.72 & 1.01 & 0.92 & 75.2 & 0.96 & 72.22 & I & 74.03 & I & 0.98 & 1.05 \\
\hline I6 & 76.71 & 1.32 & 1.17 & 75.4 & 1.05 & 79.13 & IV & 81.61 & IV & 0.97 & 1.06 \\
\hline G1 & 26.78 & 0.30 & 0.28 & 72.3 & 0.35 & 25.29 & I & 25.37 & I & 1.00 & 0.95 \\
\hline G2 & 40.33 & 0.45 & 0.42 & 75.2 & 0.50 & 37.60 & I & 37.62 & I & 1.00 & 0.93 \\
\hline G3 & 49.60 & 0.77 & 0.68 & 64.8 & 0.77 & 49.90 & I & 49.92 & I & 1.00 & 1.01 \\
\hline G4 & 64.85 & 1.00 & 0.88 & 68.2 & 0.95 & 64.82 & I & 65.43 & I & 0.99 & 1.01 \\
\hline G5 & 71.97 & 1.34 & 1.20 & 65.4 & 1.06 & 69.28 & IV & 70.46 & IV & 0.98 & 0.98 \\
\hline G6 & 39.09 & 0.48 & 0.78 & 71.3 & 0.66 & 47.05 & I & 47.64 & I & 0.99 & 1.22 \\
\hline G7 & 52.65 & 0.65 & 0.59 & 76.3 & 0.69 & 52.62 & I & 52.30 & I & 1.01 & 0.99 \\
\hline G8 & 63.27 & 1.05 & 0.92 & 69.3 & 0.96 & 66.53 & II & 68.19 & II & 0.98 & 1.08 \\
\hline $\mathrm{C} 1$ & 11.30 & 0.40 & 0.38 & 24.2 & 0.46 & 11.12 & I & 10.99 & I & 1.01 & 0.97 \\
\hline $\mathrm{C} 2$ & 15.25 & 0.71 & 0.71 & 23.8 & 0.75 & 17.85 & I & 18.23 & I & 0.98 & 1.20 \\
\hline C3 & 20.00 & 1.05 & 0.99 & 24.5 & 1.00 & 24.47 & II & 25.00 & II & 0.98 & 1.25 \\
\hline $\mathrm{C} 4$ & 25.31 & 1.51 & 1.41 & 24.7 & 1.13 & 27.86 & IV & 28.14 & IV & 0.99 & 1.11 \\
\hline $\mathrm{C} 5$ & 29.71 & 2.02 & 1.85 & 24.9 & - & - & IV & 30.47 & IV & - & 1.03 \\
\hline C6 & 34.23 & 2.51 & 2.39 & 25.4 & 一 & - & IV & 32.83 & IV & - & 0.96 \\
\hline Average & - & - & - & - & - & - & - & - & - & 0.985 & 1.050 \\
\hline $\begin{array}{l}\text { Standard } \\
\text { deviation }\end{array}$ & - & - & - & - & - & - & - & - & - & 0.012 & 0.102 \\
\hline
\end{tabular}

$(8.24 \%)$ in terms of the ratio of the difference between $f_{L y}$ and $f_{t y}$ to their average among all the specimens, and this specimen also is located near the failure boundary $I_{L}$. Specimen B1 has the largest ratio $(8.42 \%)$ but is far away from either the failure boundary $I_{L}$ or $I_{t}$; thus a consistent prediction is reached.

It can be seen from Table 2 that the torsional strengths estimated using the proposed design charts are in excellent agreement with those obtained by the softened truss model. Comparisons of the strengths obtained by the softened truss model with the measured strengths are also given in Table 2. Clearly, in terms of average, the softened truss model predictions agree quite well with the experimental results, although the standard deviation is slightly larger.

\section{CONCLUSIONS}

This paper has presented design charts, including the normalized failure mode diagram and strength contour diagram for the torsional design of reinforced concrete rectangular members. These diagrams are constructed based on the softened truss model. Therefore, the accuracy for prediction of the failure mode and the strength for a reinforced concrete member subjected to torsion is comparable to that from the softened truss model. However, the efficiency is much higher as no iterations are required. This is demonstrated by the verification example discussed above. More importantly, by the use of two newly introduced reinforcement indices, the proposed design charts are independent of the dimensions of the cross section, the yield strength of steel reinforcement, and the compressive strength of concrete. Therefore, these charts are very suitable for use in structural design offices and can be utilized conveniently as an alternative method to the current design methods.

\section{APPENDIX I. ANALYSIS AND DESIGN PROCEDURES}

Application of the proposed design charts in an analysis problem is demonstrated below using specimen B1 of Table 1. The data for specimen B1 are as follows: $x=25.4 \mathrm{~cm}, y=$ $38.1 \mathrm{~cm}, f_{c}^{\prime}=27.58 \mathrm{MPa}, f_{y}=\left(f_{L y}+f_{t y}\right) / 2=327.5 . \mathrm{MPa}, A_{L}$ $=5.07 \mathrm{~cm}^{2}, A_{t}=0.7126 \mathrm{~cm}^{2}$, and $s=15.24 \mathrm{~cm}$. Therefore, $A_{c}$ $=x y=967.74 \mathrm{~cm}^{2}$ and $p_{c}=2(x+y)=127 \mathrm{~cm}$.

From (27), $\delta_{L}=A_{L} / A_{c}=0.005239$, and from (28), $\delta_{t}=$ 
$\left(A_{t} p_{c}\right) /\left(s A_{c}\right)=0.006136$. Then, $\eta_{L}=\left(f_{y} / f_{c}^{\prime}\right) \delta_{L}=0.0622$ and $\eta_{t}=\left(f_{y} / f_{c}^{\prime}\right) \delta_{t}=0.0729$ according to (31) and (32), respectively. Next, (35) and (36) are used, respectively, to obtain $\eta_{L b}=$ $76 /\left(200+f_{y}\right)=0.1441$ and $\eta_{t b}=76 /\left(100+f_{y}\right)=0.1778$. Finally, $\phi_{L}=\eta_{L} / \eta_{L b}=0.43$ and $\phi_{t}=\eta_{t} / \eta_{t b}=0.41$ according to (33) and (34), respectively.

Knowing that $\left(\phi_{L}, \phi_{t}\right)=(0.43,0.41)$, the type of failure mode is Mode I according to Fig. 5 (or Fig. 6) and $\phi_{s}=0.48$ from Fig. 8.

From (41), $\bar{M}_{x u b}=140 /\left(300+f_{y}\right)=0.223$. From (40), $M_{x u b}$ $=\bar{M}_{x u b} f_{c}^{\prime} A_{c}^{2} / p_{c}=45.37 \mathrm{kN} \cdot \mathrm{m}$. Therefore, the torsional strength $M_{x u}=\phi_{s} M_{x u b}=22.39 \mathrm{kN} \cdot \mathrm{m}$.

The above calculations demonstrate how to use the proposed design charts to obtain the failure mode and the strength for a reinforced concrete rectangular member subjected to pure torsion. Clearly, the proposed design charts are computation efficient for this kind of analysis problem compared with the softened truss model.

For a design problem, the proposed design charts are computation efficient as well. In this case, out of all possible design variables including $x, y, f_{c}^{\prime}, f_{y}, A_{L}, A_{t}$, and $s$, some are known and some are to be determined. As usual, starting from a set of trial values for the unknowns, one needs to adjust their values so that the strength provided by the section is greater than that required and the failure mode is a desired one. For each trial design, the proposed design charts can be employed very efficiently to obtain the failure mode and the strength.

\section{ACKNOWLEDGMENTS}

The writers wish to thank the reviewers of this paper for their constructive comments and suggestions.

\section{APPENDIX II. REFERENCES}

"Building code requirements for structural concrete and commentary.", (1995). ACI 318-95 and ACI 318R-95, American Concrete Institute, Detroit.

CEB-FIP model code 1990. (1990). Thomas Telford, London.

Collins, M. P., and Mitchell, D. (1991). Prestressed concrete structures. Prentice-Hall, Englewood Cliffs, N.J.

Hsu, T. T. C. (1968). "Torsion of structural concrete-behavior of reinforced concrete rectangular members." Proc., Torsion of Struct. Concrete, American Concrete Institute, Detroit, 261-306.

Hsu, T. T. C. (1988). "Softened truss model theory for shear and torsion." ACI Struct. J., 85(6), 624-635.

Hsu, T. T. C. (1993). Unified theory of reinforced concrete. CRC, Boca Raton, Fla.

Lee, Y.-S. (1998). "Theoretical analysis of FRP strengthened reinforced concrete beams," Master thesis, Dept. of Civ. Engrg., National Taiwan University, Taipei, Taiwan (in Chinese).

Rahal, K. N., and Collins, M. P. (1996). "Simple model for predicting torsional strength of reinforced and prestressed concrete sections.' $A C I$ Struct. J., 93(6), 658-666.

Vecchio, F. J., and Collins, M. P. (1986). "Predicting the response of reinforced concrete beams subjected to shear using modified compression filed theory.' 'ACI Struct. J., 85(2), 258-268.

Wang, W., and Hsu, C. T. T. (1997). "Limit analysis of reinforced concrete beams subjected to pure torsion." J. Struct. Engrg., ASCE, 123(1), 86-94. 